\title{
POLYCYSTIC KIDNEY IN AN INFANT *
}

\author{
L. T. ROYSTER, M.D. \\ NORFOLK, VA.
}

Cases of polycystic kidney observed in infancy, with necropsy findings, are still sufficiently rare to justify the report of the following case.

\section{REPORT OF CASE}

History.-E. S., of Syrian parentage, born July 1, 1916, of healthy parents. There were several other children in the family who were well and healthy. The family history was entirely negative. There was no history of miscarriages, no luetic history of any other kind and no known exposure to tuberculosis. The child was brought to the King's Daughters' visiting nurse clinic on July 28,1916 , then 4 weeks old.

Present Illness.-The mother said that she noticed before the child was 1 week old that its abdomen was unusually large, and that she thought it had grown since then. The child had appeared uncomfortable at times. There had been no vomiting. The stools had been regular, one to three per day, and on several occasions had contained small amounts of mucus. The child had nursed well and appeared satisfied with the breast. She thought the child passed more urine than most babies. The child was small and well developed, but emaciated. Otherwise than the stools there was nothing worthy of note.

Examination.-This showed a rather poorly developed child, though fairly well nourished; length, 19 inches; weight, 8 pounds 12 ounces; temperature, 98.6. The head appeared small (no measurements taken); the abdomen was quite large (17 inches in circumference); there were two masses present, one on each side of the umbilicus. These were apparent on inspection and palpation. They were distinctly nodular in outline and firm but movable, and appeared to arise from each side of the spinal column. They nearly filled both flanks and were dull to percussion, except when some folds of intestine, distended with gas, passed over them. The heart was negative. The liver was palpable about $1 \mathrm{~cm}$. below the costal border. The spleen was not palpable. The von Pirquet test was negative and Wassermann \pm , which in our clinic is disregarded unless there are other symptoms which lead to suspicion, and in that event another test is made.

The blood showed as follows: Hemoglobin, 60 per cent.; white blood cells, 14,000 ; red blood cells not counted; polynuclear cells, 55 per cent.; lymphocytes, 42 per cent.; eosinophils, 2 per cent.

The urine, which was examined repeatedly while the child was under observation, was uniformly negative, with the exception of one time, when a faint trace of albumin was reported. The urine, however, was never obtained in large enough quantities to determine the specific gravity, although the child always appeared to pass rather large amounts.

The subsequent history is of small moment. The child continued to nurse well and the milk was of good quality. Weighing before and after nursing showed that the child received from 2 ounces on admission to 4 ounces just before death. In spite of this the child did not grow in length or increase in weight. The latter, on the day before death, was 7 pounds 13 ounces. The temperature varied little and never exceeded $100 \mathrm{~F}$. (during a mild attack of

* Submitted for publication Dec. 21, 1917. 


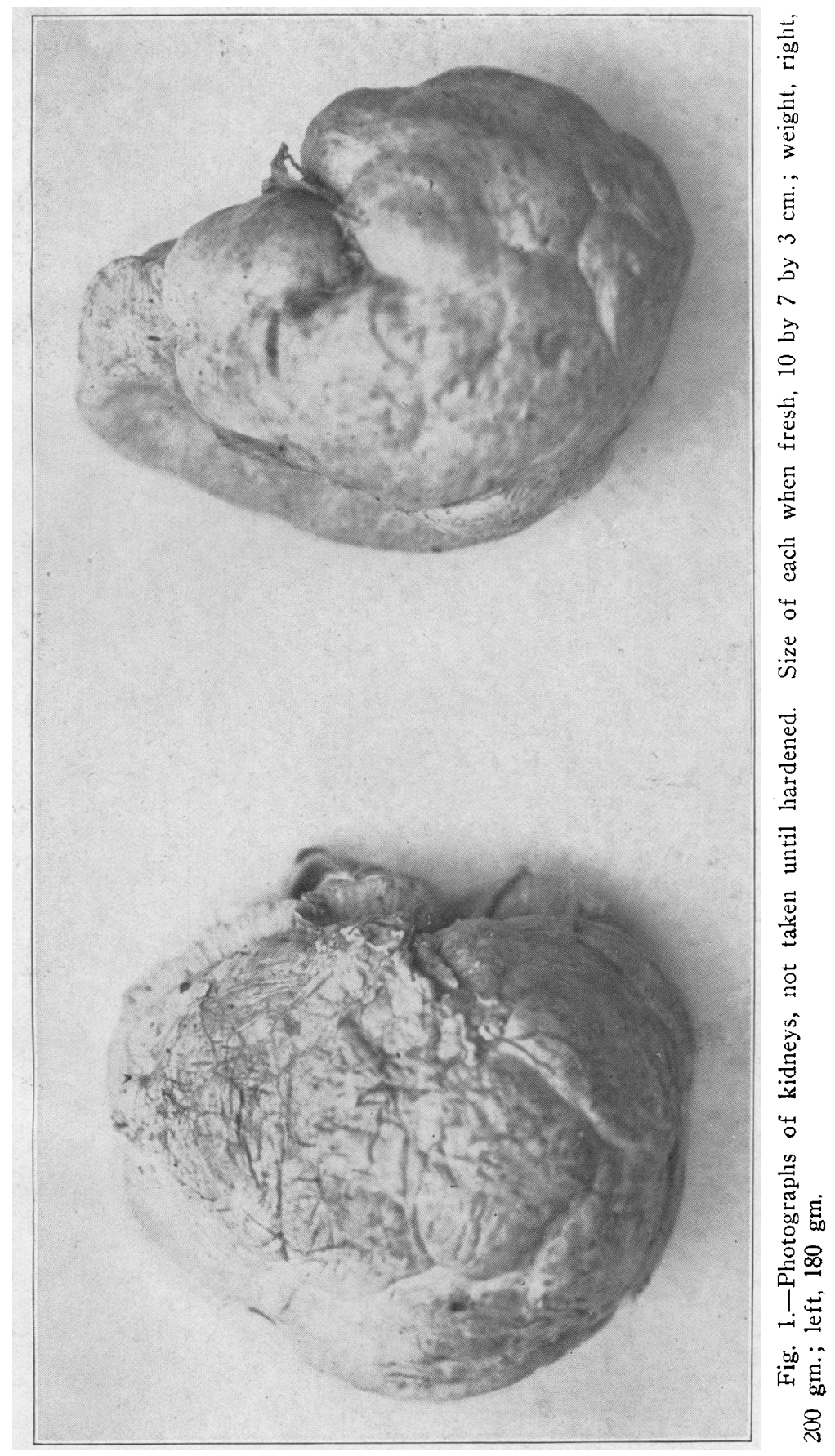




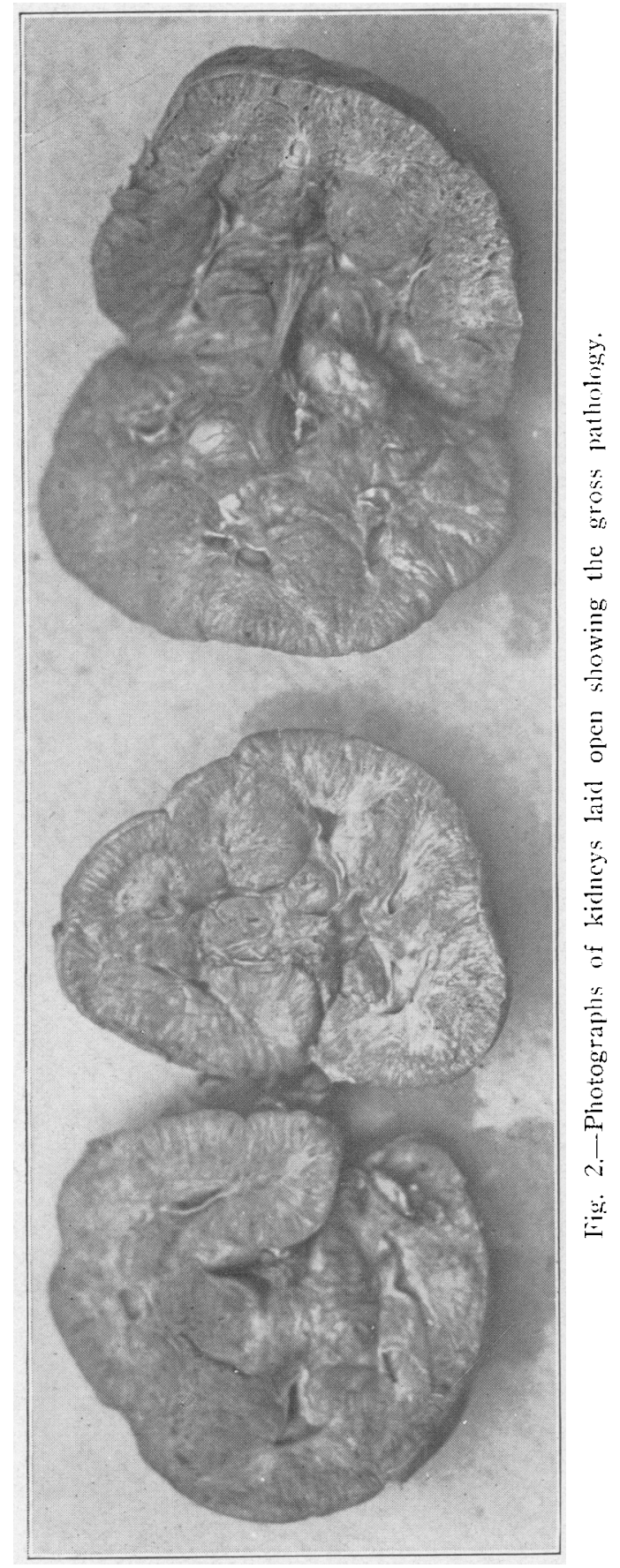


bronchitis). During the last months of life the child was very restless, appearing uncomfortable most of the time, and the mother thought there was pain.

Diagnosis.-From the negative von Pirquet, the very doubtful Wassermann and the good family history, both tuberculosis and syphilis were at once rejected. It seemed, therefore, that the diagnosis lay between sarcoma of the kidney and

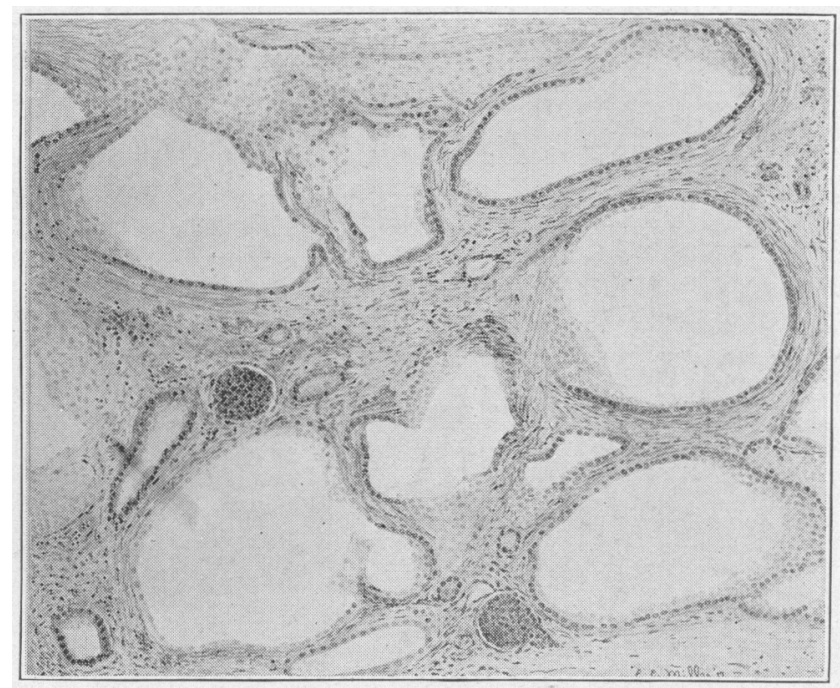

Fig. 3.-Drawing of a section of the cystic kidney, $\times 75 . \times 150$.

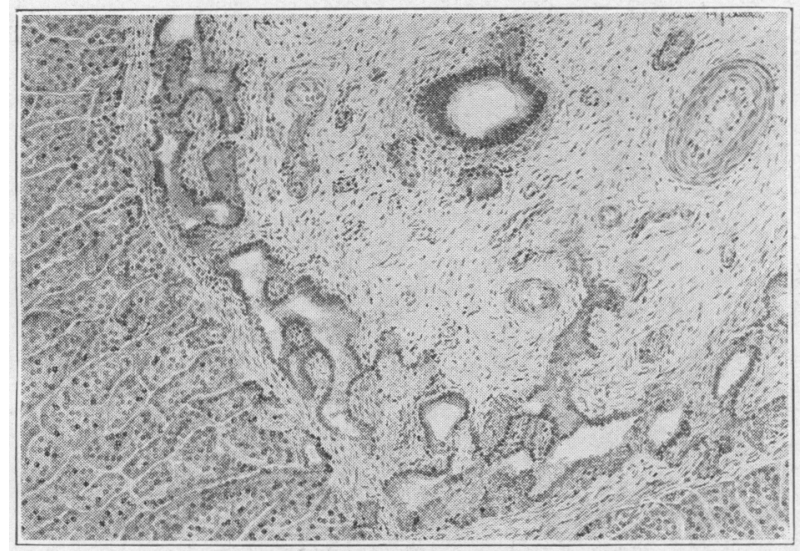

Fig. 4.-Drawing of section of liver, $\times 75 . \times 150$.

polycystic kidney. Bilateral tumors of irregular outline, dating from birth, point strongly toward polycystic kidney. We therefore made this as the probable diagnosis. The parents suggested an operation, but we felt that this was not justified.

The patient was exhibited before the Norfolk County Medical Society as a case of polycystic kidney. The child died, Feb. 27, 1917, when 8 months old. 
Necropsy.-This was performed by Dr. R. S. Kight. The pathological findings are as reported by Dr. Mary E. Roche, pathologist to the clinic.

A male child, aged 8 months; lenght, 20 inches; body very much emaciated; weight (just prior to death), 7 pounds 13 ounces; no subcutaneous fat. Heart not enlarged; abdomen distended. Lungs: Hypertrophic congestion over posterior surface of both lungs; no enlargement of bronchial lymph nodes. Abdomen: Colon distended with gas; peritoneum adherent to tumor masses in both sides of abdomen.

Kidneys: Enlarged, completely filling both sides of the abdominal cavity posteriorly from the liver to below the crest of ilium. Each kidney measured 10 by 7 by $3 \mathrm{~cm}$., and was of grayish color. They weighed 200 and $180 \mathrm{gm}$., respectively. The external surface was rough, showing raised, lobulated areas. The capsules were thickened and adherent to the kidney substance. The kidneys were soft and elastic, the surface covered with cystic elevations. varying in size from $2 \mathrm{~mm}$. to $1 \mathrm{~cm}$. in diameter. On section, the cut surface was grayish, translucent, and yellowish watery fluid exuded from the cystic areas. White connective tissue bundles radiated from the pelvis toward the cortex. The cortex was about $1 \mathrm{~cm}$. thick, with coarse striations running into the pyramids.

Liver: This organ did not extend below the costal margin. The surface was rough and nodular, resembling atrophic cirrhosis. On sectıon the connective tissue was much increased, the capsule thickened, and cut with resistance. Microscopic frozen sections showed atrophied liver cells and much connective tissue.

Taylor Building. 